\title{
LA MOTIVACIÓN EN ESTUDIANTES DE ENSEÑANZA FUNDAMENTAL Y LAS CREENCIAS Y ACTITUDES DE LOS PADRES
}

\author{
A motivação de estudantes do ensino fundamental e as crenças e atitudes dos pais
}

\author{
Selma de Cássia Martinelli ${ }^{1}$, Elaine Cristiane Aguena \\ Universidade Estadual de Campinas, Brasil \\ (Recibido el 05/04/2011 - Aceptado el 16/06/2011)
}

\begin{abstract}
RESUMEN
La literatura científica sobre la motivación en la educación viene creciendo considerablemente durante las últimas dos décadas. La familia también ha sido considerada como una importante variable en los estudios referentes al proceso de aprendizaje de los estudiantes. Considerando la importancia de estas variables, este trabajo tiene el objetivo de describir posibles relaciones entre la motivación del alumno con las creencias y las actitudes de sus padres. Participaron en este estudio 262 alumnos del $3^{\circ}$ y $5^{\circ}$ año de Enseñanza Fundamental, de ambos sexos, y sus respectivos padres, provenientes de tres escuelas de la red estatal de enseñanza de una ciudad de la provincia del Estado de São Paulo. Fueron utilizadas dos escalas de evaluación, la Escala para Evaluación de la Motivación Escolar (EAME-IJ) y la Escala de Evaluación de las Creencias y de las Actitudes de los Padres (EACAP). Los resultados de este estudio indicaron una correlación entre la motivación del alumno y las creencias de los padres.
\end{abstract}

Palabras clave: Motivación intrínseca, motivación extrínseca, padres, familia.

\begin{abstract}
Scientific literature about motivation in education is considerably growing in the last two decades. Family is being considered as an important variable in studies related to apprenticeship procedure at school. Considering the importance of these variables, this paper has as a purpose described possible relations between student's motivations and his parent's beliefs and attitudes. In this study took part 262 elementary school students from $3^{\circ}$ and $5^{\circ}$ grades of both sexes e his parents. It was used two evaluating scales: the Scholar Motivation Evaluated Scale (EAME-IJ) and the Parents Beliefs and Attitude Evaluated Scale (EACAP). This paper's results had shown a correlation between student's motivation and the parents beliefs.
\end{abstract}

Keywords: Intrinsic motivation, extrinsic motivation, parents, family.

1 Doutora em Educação na área de Psicologia Educacional pela Universidade Estadual de Campinas, Professora do Departamento de Psicologia Educacional e Coordenadora do Grupo de Estudos e Pesquisa em Psicopedagogia da Faculdade de Educação da Unicamp. Contato: Rua Bertrand Russel, 801, Cidade Universitária, Barão Geraldo, Campinas/ SP, CEP 13081-970. E-mail: selmacm@unicamp.br 


\section{INTRODUCCIÓN}

A motivação tem sido colocada no centro da discussão entre os profissionais da educação, pela simples constatação de que a sua ausência representa a queda de investimento pessoal do aluno na realização das tarefas de aprendizagem. Estudantes desmotivados estudam pouco e, consequentemente, aprendem muito pouco. A motivação no contexto escolar está relacionada com o envolvimento ativo do estudante na execução das tarefas escolares. Os efeitos imediatos da motivação do aluno consistem na aplicação de esforço no processo de aprender e na persistência demonstrada diante de cada tarefa realizada. $\mathrm{O}$ aluno desmotivado não consegue investir seus recursos pessoais, ou seja, o seu esforço na realização das atividades, fazendo apenas o mínimo e desencorajando-se diante de alguma tarefa que lhe pareça um pouco mais difícil (Bzuneck, 2004).

Os problemas de motivação escolar podem estar relacionados a dois aspectos - o quantitativo e o qualitativo (Ames \& Ames, 1984). Em termos quantitativos a motivação pode ser maior ou menor, sendo que, a motivação do aluno pode ser mais ou menos intensa. Desta forma, o aluno desmotivado é o que possui uma baixa motivação para aprender e pode apresentar um sub-rendimento e um baixo desempenho escolar. Entretanto, não se deve pensar que quanto maior e mais intensa a motivação do aluno melhor será o seu desempenho escolar. Os altos níveis de motivação no aluno podem acarretar em fadiga e ansiedade, sendo este último aspecto considerado como uma emoção negativa que poderá prejudicar a performance do estudante. A motivação ideal, no entanto, é aquela que não pode ser fraca e nem absolutamente forte, pois a baixa ou alta intensidade pode ser prejudicial à realização das tarefas escolares. Sendo assim, a motivação deve ser branda e vigilante, caracterizada mais pela qualidade do que por sua intensidade (Bzuneck, 2004).

Ainda, segundo Ames e Ames (1984) a motivação no contexto escolar pode sofrer alterações específicas de acordo com os aspectos qualitativos e o tipo de motivação que o aluno apresenta. Há alunos que se preocupam demasiadamente com as boas notas, com certificados e diplomas; outros realizam suas tarefas muito rapidamente com o único objetivo de entregar a atividade o mais rápido possível na tentativa de demonstrarem um melhor rendimento aos seus professores. Nestes casos, o que direciona o aluno não é o aprender, mas sim outros objetivos, o que pode acarretar em emoções negativas como o medo do fracasso, alta ansiedade e frustração.

No exemplo citado anteriormente, pode-se dizer que o aluno apresenta preponderantemente uma motivação extrínseca, cuja preocupação central é com a obtenção de recompensas externas de reconhecimento, e seu objetivo é atender as pressões de outras pessoas. Já o aluno que demonstra uma motivação intrínseca realiza suas atividades por ser esta interessante e geradora de alguma satisfação, seu comprometimento com a atividade é considerado espontâneo e parte do interesse individual, de modo que a participação na tarefa é a principal recompensa, enquanto as pressões externas, a obtenção de prêmios e títulos seriam condições secundárias (Harter, 1981).

De acordo com a Teoria da Autodeterminação, desenvolvida por Ryan e Deci (2000), os seres humanos são movidos por algumas necessidades psicológicas básicas que determinam as relações com o seu ambiente. Alguns estudos têm relacionado a teoria 
da autodeterminação com a motivação intrínseca, argumenta-se que as pessoas realizam as atividades por vontade própria e não por serem obrigadas ou por sofrerem pressões externas (De Charms, 1984; Deci \& Ryan, 1985). Neste caso, o indivíduo que é movido por uma necessidade própria para realizar uma determinada atividade caracteriza-se como tendo o lócus de causalidade interno. Este sujeito geralmente apresenta comportamentos intrinsecamente motivados que podem ser identificados com a possibilidade de fixar metas, planejar ações e avaliar adequadamente o seu progresso. Por outro lado, quando o indivíduo realiza suas atividades com o foco nos fatores externos este apresenta comportamentos de isolamento, sentimentos de fraqueza e ineficácia (Guimarães, 2004).

Há três necessidades psicológicas básicas, subjacentes à motivação intrínseca que são propostas pela Teoria da Autodeterminação; a necessidade de autonomia (autodireção e autodeterminação), a necessidade de competência (domínio, sentimento de eficácia) e a necessidade de pertencer (vínculo emocional). Conforme apontam Guimarães e Boruchovitch (2004), no âmbito escolar, as interações em sala de aula precisam ser fonte de satisfação destas necessidades para que a motivação intrínseca possa ocorrer e, consequentemente, para que a aprendizagem seja o objetivo principal na realização das atividades escolares.

Considerando os dois tipos de motivação do aluno (intrínseca e extrínseca), é possível encontrar na literatura uma ampla discussão sobre os determinantes das diferentes orientações motivacionais. Conforme aponta Guimarães (2004), estudos demonstram, através de seus resultados, que os alunos intrinsecamente motivados apresentam um melhor desempenho escolar, destacando que os profissionais da educação devem fazer prevalecer a motivação intrínseca dos estudantes e, que o uso de recompensas externas deve ser utilizado de forma criteriosa, evitando que o aluno seja apenas motivado extrinsecamente. Entretanto, existem pesquisadores que ressaltam o valor das recompensas externas, reconhecendo o efeito benéfico do uso adequado destas recompensas em situações de sala de aula (Ryan \& Deci, 2000; Mazineck, 2007)

Estudos voltados para a investigação dessas duas orientações motivacionais têm sido realizados, por diversos pesquisadores, para verificar a presença dessas orientações e a relação dessa variável com vários aspectos da vida dos indivíduos. Com o foco nas relações entre a motivação e o desempenho acadêmico, Martinelli e Genari (2009) investigaram estas relações em uma amostra de 150 estudantes, entre 9 e 12 anos de idade, de uma escola pública do Estado de São Paulo, que cursavam o $4^{\circ}$ e o $5^{\circ}$ ano. Os resultados dos estudantes do quinto ano revelaram uma correlação significativa e positiva entre o desempenho acadêmico e a motivação intrínseca. No quarto ano as duas variáveis caminharam de forma independentes. Em relação ao desempenho acadêmico e a motivação extrínseca, os resultados do quarto e quinto ano revelaram uma correlação significativa e negativa entre os grupos, indicando que um desempenho acadêmico mais baixo esteve associado a uma maior motivação extrínseca.

No estudo realizado por Neves e Boruchovitch (2004) investigou-se as orientações motivacionais intrínsecas e extrínsecas de alunos no contexto da progressão continuada. Participaram desta pesquisa 160 estudantes de $3^{\circ}, 5^{\circ}, 7^{\circ}$ e $9^{\circ}$ ano do Ensino Fundamental. Os resultados indicaram que quanto à motivação para estudar, mesmo sabendo que não irão 
repetir de ano, os alunos apresentaram uma orientação motivacional predominantemente intrínseca com o avançar da idade e da escolaridade.

Para os professores, a motivação do aluno é um tema que está sempre em evidência nas situações de aprendizagem, e por isso ressaltam que os alunos que estão motivados intrinsecamente na realização das tarefas escolares são aqueles que demonstram maior interesse para realizar as tarefas e empreendem maior esforço e persistência diante dos desafios o que, consequentemente, promove o seu melhor desempenho escolar. Considerase, portanto, que agenciar a motivação intrínseca do aluno é um desafio a ser enfrentado pelos professores e pais dos estudantes.

Apesar dos estudos enfatizarem com frequência a importância da escola e dos professores tanto nos aspectos motivacionais quanto no próprio envolvimento do estudante com sua aprendizagem, também tem crescido a ênfase atribuída à participação dos pais no processo de aprendizagem escolar dos estudantes (Cia, D`Affonseca \& Barham, 2004; Cia \& Barham, 2007). De acordo com Muniz e Sobel (2008), as crianças em idade escolar podem apresentar um melhor desempenho quando seus pais incentivam e apoiam a realizar as atividades acadêmicas, oferecendo-lhes responsabilidades e oportunidades para usarem suas habilidades e conhecimento. Para os autores, são vários os fatores presentes no contexto familiar que podem reduzir de modo significativo as possibilidades de uma criança sair-se bem na escola, como no caso de alunos cujas famílias não podem oferecer as condições necessárias para seu desenvolvimento e aprendizagem, o que inclui desde o material escolar, horário e local adequado em casa para o estudo e realização de tarefas, até cuidados com a saúde física e mental da criança.

Segundo Tápia (2005), a escola e a família são ambientes importantes para fortalecer o interesse do aluno na aprendizagem escolar. Para o autor, os pais e os professores devem estabelecer um ambiente agradável com base em diálogos e atitudes de suporte escolar para que a criança demonstre interesse nas atividades educacionais. Os pais podem colaborar através de diálogos com seus filhos, como por exemplo, perguntando o que fizeram na escola e auxiliando-os nas tarefas escolares.

Estudos empíricos estão, cada vez mais, relacionando o ambiente familiar com a vida escolar infantil, mais especificamente com o desempenho escolar de estudantes. Estas pesquisas indicam que determinados aspectos presentes no ambiente familiar podem relacionar-se com o processo de aprendizagem das crianças, tais como, a participação dos pais no processo de escolarização de seus filhos, a interação entre pais e fillhos, as práticas parentais, as crenças e as expectativas dos pais e o nível socioeconômico da família, dentre outros aspectos (Aunola, Nurmi, Lerkkanen \& Rasku-Puttonen 2003, Cia, D'Affonseca \& Barham, 2004; McWayne, Hampton, Fantuzzo, Cohen \& Sekino, 2004; Cia, Pamplim \& Willians, 2008; Bong, 2008; Aguena, 2010).

Atualmente também encontra-se na literatura alguns estudos que tem buscado relacionar aspectos do ambiente familiar com a motivação do estudante, indicando que o incentivo dos pais é um tipo de comportamento que pode promover o envolvimento do aluno nas atividades escolares (Raasch, 1999). De acordo com Tapia (2005) existem algumas formas de atuação dos pais que repercutem na motivação dos seus filhos para o aprender tais como acompanhar o processo de aprendizagem das crianças, ajudar seus filhos nas tarefas de 
casa e ter atitudes que podem ser consideradas como exemplos para estimular o interesse dos filhos na realização das atividades escolares.

De acordo com o resultado do estudo realizado por Veiga e Antunes (2005), que teve o objetivo de analisar a motivação escolar e os aspectos do ambiente familiar de adolescentes, a motivação geral dos alunos, sobretudo o empenho na tarefa e na percepção da competência, apresentou-se maior entre aqueles que tinham um maior apoio e suporte dos pais. Desta forma, pode-se considerar que algumas atitudes dos pais estão relacionadas com a motivação do estudante, sendo que, aqueles alunos que vivem em um ambiente estimulador, com a presença de adultos que incentivam suas capacidades, e que demonstram interesse e atitudes positivas para com o processo de aprendizagem das crianças, podem apresentar uma maior motivação para o aprender.

Considerando a importância da motivação do aluno e da família no desempenho escolar de estudantes, mais especificamente dos que cursam o Ensino Fundamental, este trabalho tem o objetivo de avaliar possíveis relações entre a motivação intrínseca e extrínseca do aluno com as crenças e as atitudes dos pais.

\section{MÉTODO}

\section{Participantes}

A amostra ficou composta por 262 estudantes com idades entre 7 e 13 anos que cursavam o terceiro $(50,4 \%)$ e quinto $(49,6 \%)$ anos do Ensino Fundamental, e seus respectivos pais, de três escolas da rede estadual de ensino de uma cidade do interior do estado de São Paulo/Brasil. Em relação ao gênero, 49,6\% dos participantes pertenciam ao sexo masculino e 50,4 \% ao sexo feminino. A amostra também ficou constituída por 16,8\% de pais e $83,2 \%$ de mães.

\section{Instrumentos}

Escala para avaliação da motivação escolar (EAME-IJ)- Martinelli e Sisto (2011)

A escala foi construída de acordo com os pressupostos da teoria da autodeterminação e propõe uma avaliação das orientações motivacionais com base nas razões que os sujeitos apresentam para realizar os trabalhos escolares. A escala é composta de 20 itens e uma estrutura de dois fatores, a saber, Motivação extrínseca (10 itens) e intrínseca (10 itens) com três alternativas de respostas para cada item (sempre, às vezes ou nunca). Quanto maior a pontuação obtida na escala maior é a motivação intrínseca ou extrínseca do aluno. Além desses dois fatores a escala também permite obter uma medida geral de motivação. A escala responde por $43,86 \%$ de variância. O coeficiente de precisão dos escores extraído por meio do Alfa de Cronbach foi de 0,84 para a motivação intrínseca e 0,91 para a motivação extrínseca. O alfa total da escala foi de 0,848. Exemplos de itens da escala: Motivação Extrínseca (ME): Eu me esforço bastante na escola para ganhar presente dos meus pais Motivação intrínseca (MI): Eu leio para aprender coisas novas

Escala de Avaliação das Crenças e das Atitudes dos Pais (EACAP) - Martinelli e Aguena (2010). 
A EACAP é uma escala que propõe avaliar as crenças e as atitudes dos pais para com os seus filhos com base em quatro fatores: crenças dos pais na capacidade e conduta dos filhos (11 itens); envolvimento parental na rotina da criança (7 itens); atitudes participativas dos pais no processo de escolarização dos filhos ( 7 itens) e suporte afetivo (6 itens). Esta escala é constituída por 31 itens, explicando $45,13 \%$ da variância e dispostos em uma escala likert de três pontos; (2) Sempre, (1) Às vezes e (0) Nunca. Esta pontuação tem seu valor invertido para os itens do Fator 2. Quanto maior é a pontuação dos pais na escala, maior é sua freqüência de crenças e atitudes positivas, sendo que a pontuação máxima desta escala é de 62 pontos. Os coeficientes de consistência interna dos fatores foram calculados e os valores do coeficiente de alpha de cronbach foram de 0,81 (fator 1), 0,84 (fator 2); 0,72 e 0,73 respectivamente para os fatores 3 e 4 e de 0,85 para a escala total. Exemplos de itens desta escala: fator 1: Eu acho que meu filho é um bom aluno; fator 2: Eu e meu filho não temos tempo para conversar; fator 3: Eu participo das reuniões escolares e fator 4: Eu converso com meu filho sobre a importância da escola.

\section{Procedimentos}

Inicialmente o projeto da pesquisa foi encaminhado ao Comitê de Ética em Pesquisa (CEP), da Universidade Estadual de Campinas/Brasil, para a aprovação do mesmo. Em seguida, com a devida aprovação do projeto pelo CEP, sob o parecer N. ${ }^{\circ} 1069 / 2008$, realizou-se o contato com a Secretaria Estadual de Educação do município, a fim de obter informações sobre as escolas que seriam as indicadas para participar do estudo.

Em reunião realizada com a direção, a coordenação e com os professores das respectivas séries, foram esclarecidos os objetivos e os procedimentos da realização da pesquisa. Para os pais que aceitaram participar da pesquisa e que também autorizaram seu filho (a) a participar, foi entregue a Escala de Avaliação das Crenças e das Atitudes dos Pais (EACAP), para que pudessem responder em casa, com o devido comprometimento de devolvê-la para a escola. Com o devido consentimento dos pais foi agendada uma data com os professores para realizar a coleta de dados com as crianças, que ocorreu na própria sala de aula e de forma coletiva. A Escala para avaliação da motivação escolar (EAME-IJ) foi aplicada pela própria pesquisadora e os participantes levaram, em média, de 30 a 40 minutos para respondê-la.

\section{RESULTADOS}

Os resultados desta pesquisa estão organizados em duas partes. Na primeira parte são apresentados os dados das análises descritivas da Escala de Avaliação da Motivação Escolar (EAME-IJ) e da Escala de Avaliação das Crenças e das Atitudes dos pais (EACAP). Na segunda parte encontram-se descritos e analisados os resultados das análises de correlação entre a motivação dos estudantes e as crenças e as atitudes dos pais.

A motivação escolar dos estudantes

A Tabela 1 apresenta as médias, o desvio padrão e a pontuação mínima e máxima da motivação intrínseca e extrínseca dos alunos. 
TABELA 1. Estatística descritiva da EAME-IJ

\begin{tabular}{cccccc}
\hline Motivação & $\mathrm{N}$ & Média & $\begin{array}{c}\text { Desvio } \\
\text { Padrão }\end{array}$ & $\begin{array}{c}\text { Pontuação } \\
\text { Mínima }\end{array}$ & $\begin{array}{c}\text { Pontuação } \\
\text { Máxima }\end{array}$ \\
\hline Intrínseca & 262 & 17,93 & 2,37 & 7 & 20 \\
Extrínseca & 262 & 9,58 & 6,08 & 0 & 20 \\
\hline
\end{tabular}

Na Tabela 1 observa-se que os estudantes demonstraram uma média alta com relação à motivação intrínseca, o que permite considerar que estes estudantes declararam estarem envolvidos com as atividades escolares, terem curiosidade, interesse e acreditarem na sua capacidade para cumprir as tarefas propostas pela escola. É possível observar também por esta Tabela que uma parte destes estudantes revelou uma alta motivação extrínseca (pontuação máxima) e também tiveram aqueles que demonstraram uma pontuação nula (pontuação mínima). Pode-se considerar que estes últimos não demonstraram estarem preocupados exclusivamente com a avaliação escolar, o reconhecimento e com a competição.

\section{As crenças e as atitudes dos pais}

A Tabela 2 apresenta as médias, o desvio padrão e a pontuação mínima e máxima dos quatro fatores da Escala de Avaliação das Crenças e das Atitudes dos Pais (EACAP).

TABELA 2. Estatística descritiva da EACAP

\begin{tabular}{lccccc}
\hline Variável - Fator & $\mathrm{N}$ & Média & $\begin{array}{c}\text { Desvio } \\
\text { Padrão }\end{array}$ & $\begin{array}{c}\text { Pontuação } \\
\text { Mínima }\end{array}$ & $\begin{array}{c}\text { Pontuação } \\
\text { Máxima }\end{array}$ \\
\hline Fator 1 & 262 & 18,99 & 2,56 & 12 & 22 \\
Fator 2 & 262 & 8,31 & 3,51 & 0 & 14 \\
Fator 3 & 262 & 10,83 & 2,18 & 5 & 14 \\
Fator 4 & 262 & 11,35 & 1,04 & 6 & 12 \\
\hline EACAP Total & 262 & 49,48 & 5,64 & 36 & 62 \\
\hline
\end{tabular}

Na Tabela 2, observa-se que a média encontrada no fator 1 (Crença dos pais sobre a capacidade e a conduta dos filhos) esteve acima do ponto médio da escala, que seria de 11 pontos, uma vez que a pontuação máxima possível nesse fator é de 22 pontos. Os resultados demonstram que, no geral, os pais declararam ter confiança na capacidade e na conduta adotada pelos seus filhos

Com relação ao fator 2 (Envolvimento parental na rotina da criança) a média foi de 8,31 pontos. Assim pode-se dizer que alguns pais não pontuaram neste fator enquanto outros alcançaram a pontuação máxima, o que significa dizer que alguns pais relataram apresentar atitudes como não conversar com os filhos e não conseguir acompanhar a rotina escolar das crianças mas a maioria declarou ter um envolvimento bastante satisfatório. 
No fator 3 (Atitudes participativas dos pais no processo de escolarização) a média foi de 10,83 num total de 14 pontos possíveis neste fator. Com base neste dado, pode-se observar que os pais revelaram uma percepção das suas atitudes como participativa no processo de escolarização dos filhos, uma vez que a média está acima do ponto médio da escala.

No que se refere ao Suporte afetivo - fator 4, a média foi de 11,35, de um total possível de 12 pontos. Neste fator os pais atingiram uma média bastante alta, o que significa dizer que de maneira geral eles elogiam os sucessos da criança e ouvem suas necessidades.

Na pontuação geral da Escala de Avaliação das Crenças e Atitudes dos Pais encontrou-se uma média de 49,48 pontos, com desvio padrão de 5,64. A variação desta escala esteve entre 32 e 62 pontos, sendo que a pontuação máxima na escala é de 62 pontos. Nesta amostra, os pais, de maneira geral, auto declararam-se com crenças e atitudes em relação aos filhos mais positivas que negativas.

As relações entre motivação e as crenças e Atitudes dos Pais

Os coeficientes de correlação, entre a motivação intrínseca e extrínseca dos estudantes e as Crenças e as atitudes dos pais, foram obtidos por meio do teste de correlação de Spearman, sendo considerado o nível de significância de 0,05 , e podem ser observados na Tabela 3 .

TABELA 3. Coeficiente de correlação entre a motivação dos estudantes e as crenças e as atitudes dos pais

\begin{tabular}{lcccc}
\hline EACAP & \multicolumn{2}{c}{$\begin{array}{c}\text { Motivação } \\
\text { Intrínseca }\end{array}$} & $\mathrm{c}$ & \multicolumn{2}{c}{$\begin{array}{c}\text { Motivação } \\
\text { Extrínseca }\end{array}$} \\
\hline Fator 1 & rs & $\mathrm{p}$ & $\mathrm{rs}$ & $\mathrm{p}$ \\
Fator 2 & $0,246^{* *}$ & $<0,001$ & $-0,235^{* *}$ & $<0,001$ \\
Fator 3 & $-0,090$ & 0,147 & $-0,084$ & 0,178 \\
Fator 4 & 0,033 & 0,595 & 0,044 & 0,483 \\
\hline EACAP total & 0,043 & 0,488 & 0,013 & 0,829 \\
\hline
\end{tabular}

*correlation is significant at the 0.05 level (2-tailed)

**correlation is significant at the 0.01 level (2-tailed)

A análise dos dados obtidos por meio da Escala de Avaliação da Motivação (EAME-IJ) e da Escala de Avaliação das Crenças e das Atitudes dos Pais (EACAP) revelou existir uma correlação significante entre a motivação intrínseca com as crenças dos pais, fator 1 ( $\left.\mathrm{rs}=0,246^{* *}, \mathrm{p}=<0,001\right)$. Este resultado revelou que quanto maior as crenças positivas dos pais na capacidade e na conduta das crianças mais os filhos se autodeclararam motivados intrinsecamente.

De forma semelhante, a análise da motivação extrínseca revelou existir uma correlação significante e negativa com as crenças dos pais, fator $1,\left(-0,235^{* *}, p=<0,001\right)$. As 
correlações negativas e significantes demonstraram que, quanto maior as crenças positivas dos pais na conduta e na capacidade dos seus filhos, menor foi a presença da motivação extrínseca nos estudantes. Os demais fatores não revelaram significância estatística com as orientações motivacionais. O resultado da análise também indicou uma correlação entre a EACAP geral e a motivação intrínseca do estudante, de modo que, as crenças e as atitudes dos pais estão relacionadas com a motivação escolar do aluno.

\section{DISCUSSÃO}

Este estudo foi motivado por indicações da literatura que apontam para o fato de que o desempenho e as atitudes dos estudantes para com a aprendizagem no contexto escolar podem estar sendo apoiadas ou influenciadas pelas atitudes e comportamentos dos pais ou responsáveis, no que diz respeito à escola e o que esta tem a oferecer a seus alunos. Desta premissa inicial derivou-se o interesse por buscar evidências empíricas sobre a motivação declarada pelo próprio aluno, para com a escola e as suas aprendizagens, e as possíveis relações entre essa motivação e as atitudes e crenças declara pelos pais em relação a seus filhos.

Os resultados deste estudo demonstraram que as crenças positivas dos pais estão relacionadas com a motivação dos estudantes, sendo que os pais que revelaram uma maior frequência de crenças positivas tiveram um relato de seus filhos demonstrando uma maior motivação intrínseca. Desta forma, pode-se considerar que quando os pais acreditam que seus filhos são bons alunos, são responsáveis e que respeitam seus amigos, entre outras situações, as crianças também revelam uma maior motivação intrínseca. Da mesma maneira, crenças mais positivas por parte dos pais também estiveram correlacionadas negativamente com a motivação extrínseca, o que significa dizer que uma boa parte destes estudantes não relatou ter como foco principal na escola apenas a obtenção de boas notas, o reconhecimento público dos demais, o ganho de recompensas, entre outras coisas.

Embora não se tenha buscado verificar se os estudantes que se declararam mais motivados intrinsecamente, e que tiveram os pais que também acreditavam em suas capacidades, eram os mesmos que pontuaram menos na motivação extrínseca, dado este que poderá ser apresentado posteriormente em um novo estudo, considera-se que esta informação seja bastante interessante para se pensar as relações entre família e escola.

A escala também prevê em seus fatores aspectos relativos aos comportamentos e as atitudes efetivamente praticados pelos pais, nesta amostra este não foi um fator que revelou correlação significante com a motivação dos estudantes. De fato os pais podem ter sido muito benevolentes ou muito punitivos consigo mesmos, no momento em que avaliaram suas atitudes, o que pode ter interferido no dado. Da mesma maneira quando se trata de avaliar o que eles pensam de seus filhos, o relato também pode ter sido menos objetivo do que se esperava. Assim também, ao avaliarem sua participação na rotina escolar de seus filhos os pais revelaram ter uma participação bastante positiva, no entanto esta percepção dos pais pode não corresponder ao percebido pelos filhos ou ao que eles consideram como relevante. Esse é um ponto deste estudo que mereceria ser melhor investigado uma vez que tem sido considerado na literatura que atitudes participativas dos pais no processo 
de escolarização dos filhos são favorecedoras da aprendizagem das crianças, o que pode interferir sobre sua motivação, fato este não confirmado no presente estudo.

Outro fato que merece destaque é o quanto as respostas dos pais podem ter sido dadas em atendimento ao que eles sabem e pensam ser o correto e esperado e não propriamente ao que de fato fazem e pensam em relação aos seus filhos. O uso desta escala associada a uma medida de desejabilidade social poderia ser bastante interessante.

Como síntese geral este estudo revelou que, o que de fato foi forte o suficiente para influenciar a vida destes estudantes foi o quanto os pais demonstravam acreditar na capacidade e na conduta de seus filhos para desempenhar-se bem na escola e ter sucesso nas suas relações interpessoais.

\section{REFERÊNCIAS}

1. Aguena, E. C. (2010). As crenças e as atitudes parentais e o desempenho escolar de alunos do Ensino Fundamental. Campinas, SP: [s.n.], 2010. Dissertação (mestrado) - Universidade Estadual de Campinas, Faculdade de Educação.

2. Aunola, K., Nurmi, J., Lerkkanen, M., \& Rasku-Puttonen, H. (2003). The roles of achievement-related behaviours and parental beliefs in children's mathematical performance. Educational Psychology, 23 (4), 403-421.

3. Ames, C. \& Ames, R. (1984). Systems of student and teacher motivation: toward a qualitative definition. Journal of Education Psychology, 76 (4), 535-56.

4. Bong, M. (2008). Effects of Parent-Child Relationships and Classroom Goal Structures on Motivation, Help-Seeking Avoidance, and Cheating. The Journal of Experimental Education, 76 (2), 191-217.

5. Bzuneck, J. A. (2004). A motivação do aluno: aspectos introdutórios. Em Boruchovitch. E, Bzuneck, J.A. (Orgs.), A motivação do aluno: Contribuições da Psicologia Contemporânea. Petrópolis, RJ: Vozes.

6. Cia, F., D’Affonseca, S. M., \& Barham, E. J. (2004). A relação entre envolvimento paterno e desempenho acadêmico dos filhos. Cadernos de Psicologia e Educação Paidéia, 14 (29), 277-286.

7. Cia, P., Pamplin, R. C. O. \& Williams, L. C. A. (2008). O Impacto do Envolvimento Parental no Desempenho Acadêmico de Crianças Escolares. Psicologia em Estudo, Maringá,13 (2), 351-360.

8. De Charms, R. (1984). Motivation enhancement in educational settings. In: C. Ames $\& \mathrm{R}$. Ames (eds). Research on motivation in education, student motivation. New York: Academic Press, 1, 275-237.

9. Deci, E. L. \& Ryan, R. M. (1985). Intrisic Motivation and self-determination in human behavior. New York: Plenum Press.

10. Guimarães, S. E. R. (2004). A organização da escola e da sala de aula como determinantes da motivação intrínseca e da meta aprender. Em Boruchovitch. 
E, Bzuneck, J.A. (Orgs.), A motivação do aluno: Contribuições da Psicologia Contemporânea. Petrópolis, RJ: vozes.

11. Guimarães S. E. R. \& Boruchovicth, E. (2004). O estilo motivacional do professor e a motivação intrínseca dos estudantes: Uma perspectiva da teoria da autodeterminação. Psicologia: Reflexão e Crítica, 17 (2), 143-150.

12. Harter, S. (1981). A new self-report scale of intrinsic orientation in the classroom: Motivational and Informational Components. Developmental Psychology, 17(3), 300-312.

13. McWayne, C., Hampton, V., Fantuzzo, J., Cohen, H. L. \& Sekino, Y. (2004). A multivariate examination of parent involvement and the social and academic competencies of urban kindergarten children. Psychology in the schools, 41 (3), 363-377.

14. Mazineck, A. (2007). A motivação de adolescentes nas aulas de educação física. Dissertação de Mestrado. Universidade Católica de Brasília.

15. Martinelli e Aguena (2010). Escala de Avaliação das Crenças e das Atitudes dos Pais $(E A C A P)$. Universidade estadual de Campinas, manuscrito não publicado.

16. Martinelli, S. C. \& Genari, C. H. M. (2009). Relações entre desempenho escolar e orientações motivacionais. Estudos de psicologia, 14 (1), 13-21.

17. Martinelli, S.C e Sisto, F.F. (2011). Escala para avaliação da motivação escolar (EAME-IJ). São Paulo: Casa do Psicólogo (no prelo).

18. Muniz, A. L. P. \& Sobel, T. F. (2008). Características das famílias de crianças trabalhadoras em Minas Gerais em 2004. Trabalho apresentado no XVI Encontro Nacional de Estudos Populacionais, ABEP, realizado em Caxambú - MG - Brasil, de 29 de setembro a 03 de outubro de 2008.

19. Neves, E. R. \& Boruchovitch, E. (2004). A motivação de alunos no contexto da progressão continuada. Psicologi: Teoria. e Pesquisa,20 (1), 77-85 .

20. Raasch, L. (1999). A motivação do aluno para a aprendizagem. Faculdade Capixaba de Nova Venécia. Diário Oficial da União, no. 1.299.

21. Ryan, R. M. \& Deci, E. El. (2000). Self-determination theory and the facilitation of intrisic motivation, social development, and well-being. American Psychologist, $55(1), 68-78$.

22. Tápia, J.A. (2005). Motivar en la escuela, motivar em la família. Madrid, Morata.

23. Veiga, F; Antunes, J. (2005). Motivação Escolar em Função da Família na Adolescência. Actas do VIII Congresso Galaico Português de Psicopedagogia (pp. 979-989). 